\title{
Positive effects of aerobic physical activity in institutionalized older subjects complaining of dyspnea
}

\author{
Mario Bo ${ }^{\mathrm{a}, *}$, Mauro Fontana ${ }^{\mathrm{b}}$, Maurizio Mantelli ${ }^{\mathrm{b}}$, \\ Mario Molaschi ${ }^{\text {a }}$ \\ ${ }^{a}$ Section of Geriatrics, Department of Medical and Surgical Disciplines, Azienda Ospedaliera San Giovanni \\ Battista-Molinette, C.so Bramante 88, 10126 Turin, Italy

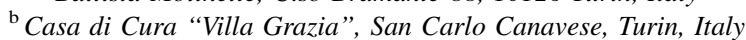

Received 31 March 2005; received in revised form 12 October 2005; accepted 14 October 2005

Available online 6 December 2005

\begin{abstract}
Dyspnea is a common complaint in older subjects, but in some patients a disease responsible for this symptom is not found. We aimed to evaluate the effects of a short program of regular aerobic physical activity on dyspnea and ability to walk in a sample of older nursing home residents without evidence of cardiac and pulmonary disease. Limitation from dyspnea in daily activities was reported by $82 \%$ of residents; $34 \%$ of these individuals did not show any evidence of cardiac or pulmonary disease. In these subjects a 4-week period of daily exercise training compared with no intervention resulted in a significant improvement of dyspnea and endurance to walking. Dyspnea is an extremely common complaint in elderly residents in long-term facilities. About one-third of these subjects do not show evidence of cardiac or pulmonary disease. In these individuals a short period of exercise training has favorable effects on dyspnea and ability to walk.
\end{abstract}

(C) 2005 Elsevier Ireland Ltd. All rights reserved.

Keywords: Dyspnea; Physical activity; Nursing home residents

\section{Introduction}

Dyspnea represents a common symptom in older subjects. An attitude to "underreporting" of dyspnea has been described in elderly subjects (Tinetti, 2003). Dyspnea may

* Corresponding author. Tel.: +39 011 6335328; fax: +390116961045.

E-mail address: mario.bo@unito.it (M. Bo).

0167-4943/\$ - see front matter (C) 2005 Elsevier Ireland Ltd. All rights reserved. doi:10.1016/j.archger.2005.10.001 
be overlooked by physicians and neglected by older patients or, more frequently, it can be attributed to some of the several diseases usually present in older patients (Dow et al., 1992; Caruana et al., 2000). However, being a subjective complaint, dyspnea is not easy to investigate in elderly subjects for several reasons. Older subjects may have a reduced perception of dyspnea, also because they naturally tend to be self-limiting in daily activities (Tinetti, 2003). On the other hand, inactivity itself may induce physical deconditioning that, in turn, makes the older subjects less tolerant to exercise and more prone to report dyspnea even for minimal or moderate efforts. This vicious circle may result in loss of autonomy and progressive immobilization. When facing dyspnea in older patients, one must consider that this symptom does not imply necessarily the presence of cardiac or pulmonary disease. Therefore, it is reasonable to expect that a program of physical training in these subjects might favourably affect the individual perception of dyspnea and/or the ability to perform daily activities. To our knowledge, there are no studies, which have investigated the effects of a program of physical activity on dyspnea unrelated to cardiac or pulmonary diseases in older subjects.

In this study we aimed to evaluate the effects of a short program of regular aerobic physical activity on dyspnea and ability to walk in a sample of older nursing home residents without evidence of cardiac and pulmonary disease.

\section{Subjects and methods}

The study was conducted in a long-term facility for elderly independent subjects in the period June-October 2003. Independence was determined through the use of the activities of daily living scale (ADL) (Katz et al., 1963). Inclusion criteria were: age of 75 year or older, absence of cognitive impairment, an age- and education-adjusted Mini Mental State Examination (MMSE) score greater than or equal to 24/30 (Folstein et al., 1975), absence of anemia (defined as an hemoglobin level $<13 \mathrm{~g} / \mathrm{dl}$ in men and $<12 \mathrm{~g} / \mathrm{dl}$ in women), renal or hepatic failure, or other severe diseases, and ability to walk without assistance.

All patients underwent a complete physical examination, including measurement of height, weight and calculation of the Body Mass Index (BMI). The prevalence of dyspnea associated with daily activities was measured using the Baseline Dyspnea Index (BDI) (Mahler et al., 1984). This is an interviewer-administered questionnaire, which evaluates dyspnea by determining the effect of this symptom on daily activities. The BDI consists of three settings (functional impairment, magnitude of task, and magnitude of effort) and each one is scored on a 0 (severe) to 4 (no impairment) scale. The three scales are summed to give the BDI focal score, which can range from 0 (the most limitation from dyspnea) to 12 (no limitation from dyspnea). This instrument takes, approximately, 3-4 min to complete (Mahler et al., 1995). In each subject, dyspnea was considered present when the BDI score was $<12$.

In order to identify subjects with dyspnea and free from cardiac or pulmonary diseases, all individuals who reported dyspnea underwent a complete medical evaluation, including review of individual medical charts, thorough physical evaluation (including determination of arterial oxygen saturation through external saturimetry), review of recent chest X-ray, and 12-lead electrocardiogram. Subjects not showing evidence of cardiac or pulmonary 
disease at this preliminary screening underwent further investigations, including transthoracic echocardiography and spirometry.

A standard transthoracic echocardiographic study was performed by a qualified cardiologist using a commercially available machine (MEGAS Esaote Biomedical System, Florence, Italy) equipped with a $2.5-$ or $3.5-\mathrm{MHz}$ annular-array transducer. Left ventricular (LV) function and LV ejection fraction (LVEF) were computed from apical 2- and 4-chamber views using the area-length method (Schiller et al., 1989). Valvular flow velocities were systematically assessed by pulse-wave and continuous-wave Doppler from the apical 4chamber view. Emodynamic parameters (pulmonary capillary wedge pressure, the cardiac index, and right atrial pressure) were systematically estimated by the Doppler technique. Spirometry was performed using a rolling seal spirometer (Vmax 20C, Sensor Medics). Lung volumes were measured with a body plethysmography. The diffusing capacity of the lung for carbon monoxide (DLCO) was measured by the single-breath technique using the abovementioned system (Vmax 22, AutoBox; Sensor Medics) and correcting for hemoglobin levels according to the European Respiratory Society recommendations (Quanjer et al., 1993). The theoretical age-adjusted reference values of the European Respiratory Society (Siafakas et al., 1995) were used for spirometric measurements.

Subjects who did not show any clinical and instrumental evidence of diseases were considered to have dyspnea without evidence of cardiac and pulmonary disease. From these subjects, two age- and sex-matched groups of patients were obtained: the intervention group, which received a 4-week period of exercise training and the control group, which did not receive specific intervention. Aims and modalities of the study were clearly illustrated to all subjects, who gave their informed consent to participation.

Dyspnea was assessed using the following tools. For exercise, the Visual Analogic Scale (VAS) (Reardon et al., 1994) was used. This consisted of a vertical $300 \mathrm{~mm}$ line with the bottom end representing no breathlessness and the top end representing the greatest level of breathlessness. The distance in millimeters from the bottom was used to rate dyspnea. This test was evaluated at rest and at the end of the 6-Minute Walking Distance (6MWD) test. Dyspnea associated with daily activities was measured using the BDI and the Transitional Dyspnea Indexes (TDI) (Reardon et al., 1994; Mahler et al., 1995; O'Donnell et al., 1995), which are interviewer-administered questionnaires. The BDI was administered at baseline, whereas the TDI was administered at the end of the period of exercise training. Changes in limitation in the areas of functional impairment, magnitude of task and magnitude of effort were rated using the TDI. Each was scored on a -3 (major deterioration) to 0 (no change) to +3 (major improvement) scale. Therefore, the focal TDI score, which is given by the sum of the three scales, can range from -9 (greatest increase in limitation caused by dyspnea) to +9 (greatest decrease in limitation caused by dyspnea).

A $35 \mathrm{~m}$ facility corridor, marked by colored tape at each end, was used for performing the 6MWD test (Guyatt et al., 1985; Enright et al., 2003). Patients were instructed to walk from end to end of corridor, attempting to cover as much distance as possible in the allotted $6 \mathrm{~min}$. A research assistant timed the walk and recorded the distance travelled, as well as heart rate for each minute of walking completed and continuous oxygen saturation through external saturimetry. Although participants were allowed to stop and rest as necessary, they were encouraged to proceed with the walk on recovery as far as possible. The 6MWD was performed at baseline and after 4 weeks in all participants. 
Patients randomised to the intervention group received daily (5 days/week) exercise training on a treadmill and stationary bicycle for 4 weeks. The goal was to achieve $30 \mathrm{~min}$ of training per session, with the target exercise level set at approximately $75 \%$ of maximum heart rate. Ten-minute warm-up (mainly dedicated to stretching and low-intensity peripheral muscle training) and 2-min cool-down periods were allowed, but they were excluded from the calculation of exercise duration. Participants were free to choose between treadmill and bicycle training, also in the same session. Short rest periods during training were allowed. The goal of training was to keep the intensity of exercise relatively constant on an individual basis, while gradually increasing the duration of exercise, which was recorded for each session. Main outcome measures were distance walked in the 6MWD test, change in dyspnea according to the TDI score, and change in VAS score after 6MWD test.

The Kolmogorov-Smirnov Test was used to evaluate distribution of variables. The Student's $t$-test was used to evaluate differences between variables. Windows XP packaging and SPSS program were used for analysis.

\section{Results}

During the study period 145 subjects were evaluated. One hundred and thirteen subjects met the inclusion criteria. Twenty-seven refused to participate and 86 subjects were eligible for the study. Limitation from dyspnea in daily activities, defined as a BDI score $<12$, was reported by 71 subjects $(82 \%)$. Clinical or instrumental evidence of cardiac or pulmonary disease were found in 47 subjects $(66 \%)$ while 24 subjects $(34 \%)$ had no evidence of cardiac or pulmonary disease. From this sample, 22 subjects ( 6 men, 16 women, mean age $79.4 \pm 1.9$ year) were enrolled in the intervention study and were allocated in two sexmatched groups (intervention versus control, each one of 11 subjects). The most common diseases in this sample of subjects were hypertension (in 14 subjects), arthrosis (in 10 subjects), and type 2 diabetes (in four subjects). Table 1 shows the main baseline characteristics of participants. No significant differences between the two groups were observed at baseline. Mean MMSE and ADL score were 27.9 and 6.5, respectively. Slight to moderate dyspnea in daily activities was observed in both groups, while the symptom was absent at rest in most of subjects.

Table 1

Baseline characteristics of participants

\begin{tabular}{lcc}
\hline & Intervention group $(n$ 11) & Control group $(n 11)$ \\
\hline Age (years) & $80.1 \pm 2.1$ & $79.1 \pm 1.8$ \\
Male/female, gender (number) & $3 / 8$ & $3 / 8$ \\
BMI $\left(\mathrm{kg} / \mathrm{m}^{2}\right)$ & $21.5 \pm 2.6$ & $22.3 \pm 1.9$ \\
MMSE (score) & $28.1 \pm 2.0$ & $27.9 \pm 2.1$ \\
ADL (score) & $6.6 \pm 0.5$ & $6.5 \pm 0.5$ \\
VAS dyspnea, at rest (mm) & $24 \pm 5$ & $23 \pm 6$ \\
VAS dyspnea, after 6MWD (mm) & $115 \pm 47$ & $118 \pm 39$ \\
BDI (U) & $8.3 \pm 1.4$ & $8.2 \pm 1.6$ \\
6MWD (m) & $282 \pm 58$ & $261 \pm 46$ \\
\hline
\end{tabular}

Data are presented as mean \pm S.D. unless otherwise indicated. 
Table 2

Changes in variables from baseline

\begin{tabular}{llccl}
\hline & $\begin{array}{l}\text { Intervention } \\
\text { group }\end{array}$ & $\begin{array}{l}P \text { value vs. } \\
\text { baseline }\end{array}$ & $\begin{array}{l}\text { Control } \\
\text { group }\end{array}$ & $\begin{array}{l}P \text { value vs. } \\
\text { baseline }\end{array}$ \\
\hline VAS dyspnea, at rest (mm) & $-3.0 \pm 0.7$ & 0.49 & $2 \pm 0.4$ & 0.38 \\
VAS dyspnea after 6MWD (mm) & $-48 \pm 9$ & $<0.01$ & $3 \pm 0.7$ & 0.29 \\
6MWD (m) & $52 \pm 19$ & $<0.01$ & $-17 \pm 13$ & 0.33 \\
TDI (U) & $2.1 \pm 0.4$ & $<0.01$ & $-0.3 \pm 0.1$ & 0.48
\end{tabular}

Data are presented as mean \pm S.D.

At baseline, only 11 subjects (six in the intervention group and five in the control group) were able to walk for $6 \mathrm{~min}$. The main reason for interruption was dyspnea, which was reported by four subjects in the intervention group and by five patients in the control group. The mean distance walked at baseline was $282 \mathrm{~m}$ in the intervention group and $261 \mathrm{~m}$ in the control group. In the intervention group, average external oxygen saturation at baseline was $97.3 \%$ at rest, $94.8 \%$ at the top of the $6 \mathrm{MWD}$ test and $95.6 \%$ after two-min recovery. The corresponding numbers, in the control group were $96.8 \%, 93.7 \%$, and $96.0 \%$, respectively. Heart rate measured at the same intervals at baseline were 76, 108, and $89 \mathrm{bpm}$, respectively, in the intervention group, and 79, 111, and $90 \mathrm{bpm}$ in the control group.

In the intervention group, the average time spent in exercise training was 8.4 min at baseline, $10.7 \mathrm{~min}$ at the end of the first week, $11.3 \mathrm{~min}$ at the end of the second week, $15.8 \mathrm{~min}$ at the end of the third week, and $18.7 \mathrm{~min}$ at the end of the study period.

Table 2 shows changes in variables from baseline in the two groups. At the end of the study period, one subject in the intervention group and four in the control group were not able to walk for $6 \mathrm{~min}$. The mean distance walked was significantly increased only in the intervention group (334 m versus $244 \mathrm{~m}$ in the control group). Dyspnea after 6MWD was significantly reduced from baseline in the intervention group but not in the control group (VAS dyspnea $67 \mathrm{~mm}$ versus $121 \mathrm{~mm}$, respectively). The TDI score was significantly improved in the intervention group $(2.1 \pm 0.7)$ and unchanged in the control group. External oxygen saturations at rest, at top of 6MWD and after 2-min recovery were $97.6 \%, 95.8 \%$, and $96.8 \%$, respectively, in the intervention group, and 96.7\%, 93.8\%, and $95.8 \%$ in the control group. Heart rate measured at the same intervals were 72,102 , and $82 \mathrm{bpm}$, respectively, in the intervention group, and 80,113, and $91 \mathrm{bpm}$ in the control group.

\section{Discussion and conclusions}

Results of the present study show that aerobic regular physical exercise is effective in reducing dyspnea (measured either with VAS and TDI) and improving the distance walked (measured by the 6MWD) in elderly nursing home residents without evidence of cardiac or pulmonary disease. Dyspnea is a frequent complaint in elderly subjects. However, being a subjective symptom, it is not easy to evaluate, especially in older people. Most subjects reporting dyspnea have clear evidence of diseases responsible for 
this symptom. Nevertheless, some elderly subjects may complain of dyspnea, mainly during exercise, without evidence of cardiac or pulmonary diseases accounting for this symptom. In these subjects, this unpleasant perception of breathing during an effort might be the consequence of physical deconditioning rather than the clinical expression of a disease. Sedentary lifestyle and physical inactivity are common habits in older people, and for several reasons, they are especially frequent among subjects living in long-term facilities. Our results suggest that in these subjects a short period of exercise training may produce favorable effects either on perception of dyspnea or on the ability to walk.

Although several studies have clearly demonstrated the benefit from exercise conditioning in patients with pulmonary diseases (Normandin et al., 2002; Ries et al., 1995), to our knowledge there are no studies, which investigated the effect of exercise training on dyspnea and ability to walk in elderly healthy subjects. Previous epidemiologic studies have demonstrated that walking ability is a valid indicator of physiologic reserve in older adults (Newman et al., 2003). The independent contribution of both clinical and subclinical disease to walking time supports the use of walking tests as a summary measure of disease in older adults (Newman et al., 2003). Most independent elderly persons can quickly and safely perform a 6MWD test, which can be used clinically to evaluate the impact of multiple comorbidities (Enright et al., 2003). Moreover, the independent association of walking time with physical activity supports that it is sensitive to levels of fitness as well. In this view, the favorable effects observed in subjects who underwent this short period of physical training are of particular interest. Previous studies have highlighted the importance of physical activity in maintaining health and function (Galloway and Jokl, 2000), as well as the close relationships between physical activity, self-esteem, and selfefficacy in older subjects (McAuley et al., 2000). Our findings reinforce evidence from these studies even in these oldest-old subjects, and should prompt a program of physical training for healthy older residents in long-term facilities.

Several factors should be considered when interpreting these data. Firstly, subjects who underwent the physical training period were a sample obtained from a larger group of patients after exclusion of patients with cardiac, pulmonary or other severe diseases, and therefore, results may not be generalized to these individuals. Secondly, since it was impossible to plan such an intervention as a blind-study, we cannot exclude the possibility that motivational factors in the intervention group may have also influenced results. Another potential weakness of the present study may lie in the procedure used to identify and exclude patients with cardiac and pulmonary diseases. In the oldest-old the boundaries between true pathology and senile decline are extremely ephemeral. However, we are quite confident that the "stepwise" procedure adopted (review of clinical charts, chest X-ray, electrocardiogram, and in patients without evidence of disease at this screening, further spirometric and echocardiographic evaluation) should have selected a sample of individuals free from significant cardiac and pulmonary diseases. Finally, the limited number of patients enrolled might reduce the power of our findings, although the casecontrol design reinforces our findings.

In conclusion, a short period of aerobic exercise training may be effective in reducing dyspnea and improving ability to walk in older nursing home residents without evidence of cardiopulmonary disease. 


\section{References}

Caruana, L., Petrie, M.C., Davie, A.P., McMurray, J.J., 2000. Do patients with suspected heart failure and preserved systolic function suffer from "diastolic heart failure" or from misdiagnosis? A prospective descriptive study. Br. Med. J. 321, 215-218.

Dow, L., Coggon, D., Campbell, M.J., Osmond, C., Holgate, S.T., 1992. The interaction between immunoglobulin E and smoking in airflow obstruction in the elderly. Am. Rev. Respir. Dis. 146, 402-407.

Enright, P.L., McBurnie, M.A., Bittner, V., Tracy, R.P., McNamara, R., Arnold, A., Newman, A.B., 2003. The 6min walk-test: a quick measure of functional status in elderly adults. Chest 123, 387-398.

Folstein, M.F., Folstein, S.E., McHugh, P., 1975. Mini Mental State Examination: a practical method for grading the cognitive state of patients for the clinicians. J. Psychiatr. Res. 12, 189-198.

Galloway, M.T., Jokl, P., 2000. Aging successfully: the importance of physical activity in maintaining health and function. J. Am. Orthop. Surg. 8, 37-44.

Guyatt, G., Sullivan, M., Thompson, P., Fallen, E.L., Pugsley, S.O., Taylor, D.W., Berman, L.B., 1985. The 6minute walk: a new measure of exercise capacity in patients with chronic heart failure. Can. Med. Assoc. J. 132, 919-923.

Katz, S., Ford, A.B., Moskowitz, R.W., Jackson, B.A., Jaffe, M.W., 1963. Studies of illness in the aged. The index of ADL, a standardized measure of biological and psychosocial function. J. Am. Med. Assoc. 185, 914-919.

Mahler, D.A., Weinberg, D.H., Wells, C.K., Feinstein, A.R., 1984. The measurement of dyspnea: contents, interobserver agreement, and physiologic correlations of two new clinical indexes. Chest 85, 751-758.

Mahler, D.A., Tomlinson, D., Olmstead, E.M., Tosteson, A.N., O’Connor, G.T., 1995. Changes in dyspnea, health status, and lung function in chronic airway disease. Am. J. Respir. Crit. Care Med. 151, 61-65.

McAuley, E., Blissmer, B., Katula, J., Duncan, T.E., Mihalko, S.L., 2000. Physical activity, self-esteem, and selfefficacy relationships in older adults: a randomised controlled trial. Am. Behav. Med. 22, 131-139.

Newman, A.B., Haggerty, C.L., Kritchevsky, S.B., Nevitt, M.C., Simonsick, E.M., 2003. Walking performance and cardiovascular response: associations with age and morbidity. The Health, Age and Body Composition Study. J. Gerontol. A Biol. Sci. Med. Sci. 58A, M715-M720.

Normandin, E.A., McCusker, C., Connors, M.L., Vale, F., Gerardi, D., Zuwallack, R.L., 2002. An evaluation of two approaches to exercise conditioning in pulmonary rehabilitation. Chest 121, 1085-1091.

O’Donnell, D.E., McGuire, M., Samis, L., Webb, K.A., 1995. The impact of exercise reconditioning on breathlessness in sever chronic airflow limitation. Am. J. Respir. Crit. Care Med. 152, 2005-2013.

Quanjer, P.H., Tammeling, G.J., Cotes, J.E., Pedersen, O.F., Peslin, R., Yernault, J.C., 1993. Lung volumes and forced ventilatory flows. Eur. Respir. J. 6 (Suppl. 16), 5-40.

Reardon, J., Awad, E., Normandin, E., Vale, F., Clarck, B., Zuwallack, R.L., 1994. The effect of comprehensive outpatient pulmonary rehabilitation on dyspnea. Chest 105, 1046-1052.

Ries, A.L., Caplan, R.M., Limberg, T.M., Prewitt, L.M., 1995. Effects of pulmonary rehabilitation on physiologic and psychosocial outcomes in patients with chronic obstructive pulmonary disease. Ann. Intern. Med. 122, 823-832.

Schiller, N.B., Shah, P.M., Crawford, M., De Maria, A., Devereux, R., Feigenbaum, H., Gutgesell, H., Reichek, N., Sahn, D., Schnittger, I., 1989. Recommendations for quantitation of the left ventricle by two-dimensional echocardiography. J. Am. Soc. Echocardiogr. 2, 358-365.

Siafakas, N.M., Vermeire, P., Pride, N.B., Paoletti, P., Gibson, J., Howard, P., Yernault, J.C., Decramer, M., Higenbottam, T., Postma, D.J., 1995. Optimal assessment and management of chronic obstructive pulmonary disease (COPD). The European Respiratory Society Task Force. Eur. Respir. J. 8, 1398-1420.

Tinetti, E., 2003. Approach to clinical care in the older patient. In: Hazard, W.R., Blass, J.P., Halter, J.P., Ouslander, J.G., Tinetti, M.E. (Eds.), Principles of Geriatric Medicine and Gerontology. fifth ed. McGraw Hill, New York, pp. 95-99. 